Why we should stop measuring performance and well-being

\author{
P. Matthijs Bal \\ University of Lincoln, United Kingdom
}

Author note

Matthijs Bal, Lincoln International Business School, University of Lincoln, Lincoln LN6

7TS, United Kingdom. Email: mbal@lincoln.ac.uk; +44-1522-835341.

Paper accepted for publication in Zeitschrift für Arbeits- und Organisationspsychologie/German Journal of Work and Organizational Psychology 


\title{
Why we should stop measuring performance and well-being
}

\begin{abstract}
In this essay, I argue that work and organizational psychology needs to move beyond measuring performance and well-being as the only outcomes relevant to our research. I outline the main difficulties with a narrow focus on performance and well-being, and argue that we need to broaden our scope of outcomes to stay relevant in a rapidly changing society. One example includes a dignity-paradigm, which postulates that there may be other outcomes in work and organizational psychology research which are relevant for both researchers, practitioners and society.
\end{abstract}

Keywords: work and organizational psychology, performance, well-being, critique, dignity. 
In work and organizational psychology research, there are usually two outcomes relevant: performance and well-being (Kozlowski et al., 2017). This is notable not only in theoretical models, choice of variables when collecting data, but also more implicitly in thinking, personal and professional ideologies. On the one hand, it has been argued widely that the sole purpose of individuals in the workplace is to enhance performance of organizations (see e.g., Dalal, 2005). If organizations are not profitable, they go bankrupt, and people lose their jobs. Hence, it is important to focus on performance, because it is the glue that holds everything together, and ultimately our capitalist system depends on it.

On the other hand, it is widely acknowledged that the focus on organizational performance is insufficient and that it is also worthwhile to promote employee well-being (see e.g., van de Voorde et al., 2012). Well-being is a convenient concept, because nobody can be against it, and is universally applicable; almost everyone will be in agreement that well-being is important. Positive psychology goes even one step further and claims that we should be focusing on happiness (Cabanas \& Illouz, 2019). People should follow their dreams and passions, so that they can be happy, and this can be found at work. There are also pragmatists, who believe that organizations can achieve both high performance and wellbeing, and scholars should strive towards this. This entails the utopia where organizations function well, and where people are highly performing and feeling healthy, happy and vigorous.

So what is the problem? The most fundamental problem is the lack of critical thinking towards these concepts, as they are merely taken for granted in research. However, we as Work and Organizational Psychologists (WOPs) hardly ever discuss what the effects are of our narrow focus on performance and well-being. In this essay I argue that there are fundamental problems not only with performance, but also with well-being. One could even argue that inclusion of well-being legitimizes a performance-paradigm, as it allows to 
counteract any critique on performance by postulating that there is a lot of research on employee well-being (see e.g., Bal \& Dóci, 2018, Dóci \& Bal, 2018). Hence, a critique of performance in our field cannot be conducted without taking well-being into account.

This following piece will provocatively explain why we should stop measuring performance and well-being. I speak as WOP myself, being part of the community and speaking to other WOP-scholars. I will also present some alternatives, because we need to know what to do if we do not have to worry about measuring performance and well-being in our research anymore. Yet, I wish to emphasize that I am not against performance or wellbeing as such. Performance and well-being are important, but we are currently obsessed with it, and therefore we have developed a tunnel vision (i.e., performance and well-being are the only outcomes that matter at work; see e.g., Kozlowski et al., 2017), and we have stopped to be critical of our own concepts.

\section{WOP's Myopic Focus on Performance}

WOP-research has incorporated performance as the ultimate outcome of our research; any concept in the field, such as an HR-system, mindfulness, job crafting, bullying, or psychological contract, aims to explain variance in performance. Individual performance is important, as the assumption is that it will lead to organizational performance, and in extension, that individual and team performance equal organizational performance. However, it is neglected that this obsession with performance has been complicit in a wide range of societal problems. While performance for a (private) organization equals profitability and shareholder value, it ultimately instrumentalizes anything for the pursuit of these goals. This is inherent to capitalism, as capitalism can only exist by eternal economic growth which makes anything in the world instrumental to it (Žižek, 2014). Consequently, our planet, animals, and people are sacrificed for the pursuit of profit and thus organizational 
performance. Our global neo-colonial system is maintained where in the Global South millions of people live in poverty and where children have to work in the most horrific circumstances because profit needs to be generated (Stiglitz, 2012). Why is performance then so problematic that it leads to global exploitation of our planet, people and animals?

\section{Some Problems with Performance}

The main problem is that performance in itself does not have an intrinsic meaning. Performance is purely utilitarian: it is instrumental and can be used in any context to denote behavior as a 'performance' without any judgment of its content. Performance is usually measured as doing what is in someone's task description, regardless of whether this is actually the right thing to do. Meaning is not self-evident; it has to be theorized, and explicitly included in how performance is measured. Without this, performance is merely instrumental to profitability and thereby legitimizing abuse of it for the sake of exploitation. This is also due to the hegemonic functionalist-positivist tradition of WOP, which causes us to believe that performance is merely descriptive and not normative. However, we simply cannot measure in-role performance of bankers and perceive it as something inherently good, when at the same time their performance may include offshoring profits to tax havens. This has no intrinsic human value.

In extension, it has been often neglected that a myopic focus on performance has a range of perverse effects. It does not only contribute and legitimize exploitation around the world, it also may lead to abuse and competition in the workplace. When performance is all that matters, anything is permitted, as the question pertains not to how (i.e., at what costs) performance is achieved (for an organization, management, or society), but merely how high the performance is. In achieving high performance, little is asked about the externalities of this focus on performance. When managers prioritize performance above anything, they may 
abuse subordinates or bully others. Employees have to outperform other individuals. Our way of conceptualizing performance does not promote collaboration but is always aimed at competing with each other, and to be the best.

Looking at how performance is measured, it does not directly show an intrinsic meaning of performance. First, the analysis of performance at work tends to be crosssectional, and thus, comparative. Performance of a number of individuals at work (or teams or organizations) is measured, and compared to other individuals and related to a predictor. In this way, performance is by definition comparative: it is determined why and how highperformers are 'better' than others. In extension, it also supports authoritarian views of workplaces. For instance, the most well-known (individual) performance measure of Williams and Anderson (1991; more than 6,500 citations at Google Scholar), includes items such as: "Adequately completes assigned duties" and "performs tasks that are expected of him/her". Such items measure compliance but do not measure whether work behavior leads to greater dignity of people, organizations, and the planet. It does not ask people to reflect on the intrinsic meaning of their work. It merely asks whether they do what their organization tells them to do.

One might argue that there are many new forms of performance, such as creativity, proactive behavior, OCBs, and job crafting. These performance-indicators explicitly move beyond the dictated, top-down nature of performance. Yet, it does not make them less harmful in its ideological nature. On the one hand, they represent a creative way to broaden the terminology of instrumental performance-related concepts. On the other hand, it is precisely because employees are nowadays expected to be creative and proactive, that the boundaries of what is legally and ethically possible are tested (e.g., bankers who were pushed to be 'creative' designed the financial innovations that contributed to the economic crisis of 2008; Stiglitz, 2012). 
A standard response to the criticism above would be that this focus on performance is in itself not too bad, as long as it is not detrimental for employee well-being. However, this trade-off between performance and well-being is part of the very problem, as it does not address the inherent problem of performance (e.g., lack of intrinsic meaning), and it positions and thereby legitimizes well-being as the ultimate priority of WOP. However, a myopic focus on well-being is not without problems either.

\section{Some Problems with Well-Being}

Well-being at work can be measured in multiple ways, including direct measures (e.g., health and subjective well-being) and indirect measures (e.g., organizational commitment or work engagement). Usually, well-being is investigated in WOP-research because it is a precursor of performance. This is quite prominent in indirect measures, such as organizational commitment. These are primarily of interest due to their instrumental nature, while it is much less clear why organizational commitment would be beneficial for human beings. Direct well-being measures are less problematic in this regard. With fields of research on this topic, and entire journals filled with research on this (e.g., Work \& Stress, Journal of Occupational Health Psychology), it seems as if the field as such has legitimized its own existence.

Well-being research is important in many different ways (e.g., well-being for a child working in a tin mine has a fundamental different meaning than for a Western white collar worker). Well-being is also an important outcome of power struggles and structural exploitation. However, this reveals the problem of WOP: the more problematic and contested aspects in the workplace, such as power and exploitation, are usually neglected. In contrast, well-being has been integrated in the capitalist neoliberal performance paradigm as discussed above and elsewhere (Bal, 2017; Bal \& Dóci, 2018). This perspective on well-being co-aligns 
with our current dominant perspective on society, where well-being is praised as inherently good in itself, the ultimate goal of life, and at the same time, this never realizable fantasy that motivates us perpetually to do more and more.

What we observe here is the first limitation of well-being: we do not think about the state of high well-being and its (philosophical) implications. Psychology has traditionally favored the negative aspects of well-being, as its dynamics are clear: people feel miserable and something needs to happen. But what happens when we have reached a state of high well-being? What does it bring us? Does high well-being mean more quality of life? The absence of readily available answers in our work denotes that we do not really think about these issues, as they might indicate that well-being in itself is a flawed objective, despite current wisdom in WOP.

And there are also more general problems with prioritizing well-being in WOPresearch. As long as employee well-being is optimal, WOP-scholars have 'succeeded'. Hence, it is no problem to prioritize people over the planet, and that is the explanation for why there are no fundamental problems in researching oil company employees: they show how important it is to treat employees well, and to protect their well-being. That they at the same time destroy our natural resources and the planet, is not of concern, because the wealth they have accumulated by exploiting our natural resources enables them to build up wellfunctioning HR-systems which are exemplary for work and teaching in WOP.

But even when well-being could be achieved without externalities, it still has its inherent flaws. Most fundamentally, it neglects human life as it is. Life on earth implicates suffering, and suffering is a central aspect of human life. Every day since humans have existed on the planet, wars have been fought, disease has wiped out whole people, and injury, rape, sickness, death, and emotional suffering are part of our everyday experiences. It is a fallacy to assume that by focusing on enhancing well-being (at work), suffering can actually 
be taken away. A narrow focus on well-being is too limited to understand what it is to be a human at work.

It is also ascertained that a lack of well-being indicates a 'problem': when people do not experience optimal well-being, there is something that needs to be 'fixed'.

Notwithstanding the potential impossibility of fixing this, high well-being in itself does not necessarily indicate a solution. Well-being is also affected by cognitive dissonance, as people could 'tell' themselves that they should be feeling well. This creates the perpetual paradox of contemporary society where people search for well-being and happiness, but because they never find real well-being and happiness, continue to long and search for it (Cabanas \& Illouz, 2019).

Moreover, the importance of lack of well-being is also neglected. Well-being may be beyond an individual's control (which is the case with many illnesses). To indicate lack of well-being as a 'problem that needs to be fixed' overestimates the possibility to enhance wellbeing, especially amongst those whose well-being is beyond their control. More fundamentally, a lack of well-being is enormously important in the wider social context. Depression is a necessary state of affairs in contemporary society, just as burnout is in the contemporary workplace. Hence, the question is not how to 'solve' depression and burnout, and how to fix people who experience burnout, but the right question should be: what does the burnout epidemic tell us about the contemporary workplace? Lack of well-being is important, not just to understand that well-being is not an individual experience, but a necessary step towards societal change. In other words, depression is informative, not just to indicate that people have to protect their well-being, but to understand the severity of our predicament. In the context of climate change, ever-increasing income inequality, populism, neoliberalism, and individualism (Bal, 2017), it could even be argued that we have a duty to depression, to understand the severity of our societal predicament. 
Depression and burnout are therefore also symptoms of 'disavowal': we know that our ways of living give us material richness at the expense of destruction of the planet and exploitation of people worldwide, but we nonetheless are still doing it (Žižek, 1989). Our ways of living and working are unsustainable and destroying the planet, but we persist in it because we do not see how we can get out of it. Hence, feelings of depression serve an important purpose, as they direct towards the feelings of guilt inherent to contemporary working. While depression obviously may have various deleterious effects, it cannot be underestimated and treated as if a merely individualized phenomenon that should be individually treated (with medicine or therapy).

\section{Some Alternatives}

Organizations cannot exist without performance and well-being. People need to be able to perform for an organization to exist, and people need well-being to do their jobs. However, organizations cannot not exist in the long run when the planet is depleted of its resources. Organizations have no right to exist if they exploit natural resources, the environment, people, and animals. Yet, they do, and WOP-scholars ignore those tensions in their focus on performance and employee well-being. This is also due to WOP-scholars having a rather limited implicit 'theory of the firm' as an economic entity that merely exist for profit (Melé, 2012). Is there a way out?

It is needed to introduce new ways of thinking about the outcomes of WOP-research. It is important to state that 'outcomes' is a positivistic term. However, it is needed to debate the focus of our research, or that what we want to contribute to in relation to our stakeholders, including society. First, work has a much broader meaning to people than merely to produce and serve corporate interests. However, it is needed to move beyond trite and hegemonic 
conceptualizations of meaningful work, towards a revaluing of work as an intrinsic activity, and valued as such by WOP-scholars (Lefkowitz, 2008).

However, work is not just about the individual performing it and meaningfulness, as meaning (in life) does not have to be derived from having a job. More importantly, as WOPscholars we need to ask ourselves what is currently needed in our societies and workplaces, and subsequently focus on these issues. First, we know that business in neoliberal capitalism is largely responsible for the continuous high carbon emissions and destruction of the planet. It is needed to investigate how work behavior contributes to protection and restoration of the planet, thereby radically going beyond limited concepts such as 'pro-environmental behavior', and investigate how individuals and collectives may contribute to protection and restoration of the planet. The same argument could be made for social injustice, racism, inequality, neoliberalism, individualism, and others: much more radical questions are needed.

So alternative outcomes are desperately needed, such as how individuals can contribute to greater social cohesion (in the workplace and beyond), protection of people inand outside organizations, social belonging, vibrant and inclusive communities, and so on. To do so, it is needed to stop letting organizations dictate research agendas. Well-meaning scholars often talk about the research-practice gap. However, bridging this gap does not mean simply implementing organizational agendas in research and focusing on narrow organizational goals such as performance and employee well-being. Editors and reviewers should reject papers that are merely studying these trite outcomes linking it to whatever predictor.

Frameworks that could be informative is are Melé's (2012) work on firms as 'communities of persons', and my own work on workplace dignity (Bal, 2017; Bal \& De Jong, 2017, 2018). For instance, the concept of workplace dignity describes how everything that is part of the workplace has its intrinsic, inviolable worth and meaning, including people, 
animals, the environment, natural resources, buildings, tools and finance. If it is acknowledged that everything has an intrinsic worth, new questions can be raised. For instance, research could investigate how cultures within organizations can be created where questions about the protection of dignity are normalized, and where people can work towards organizations that actively protect and promote the intrinsic worth of people and the planet. In sum, WOP-scholars are invited to think much more creatively about the outcomes of research, and that what truly matters for individuals and society.

\section{References}

Bal, M. (2017). Dignity in the Workplace: New Theoretical Perspectives. Basingstoke, UK: Palgrave MacMillan.

Bal, P.M., \& De Jong, S.B. (2017). From human resource management to human dignity development: a dignity perspective on HRM and the role of workplace democracy. In: M. Kostera \& M. Pirson (eds.), Dignity and Organizations (pp. 173-195). Basingstoke, UK: Palgrave McMillan.

Bal, P.M., \& De Jong, S.B. (2018). Create more value for all: a human dignity oriented approach to consulting. In: G. Manville, O. Matthias, \& J. Campbell (eds.), Management Consultancy Insights and Real Consultancy Projects (pp 39-50). Abingdon, UK: Routledge.

Bal, P. M., \& Dóci, E. (2018). Neoliberal ideology in work and organizational psychology. European Journal of Work and Organizational Psychology, 27, 536-548.

Cabanas, E., \& Illouz, E. (2019). Manufacturing happy citizens: How the science and industry of happiness control our lives. John Wiley \& Sons. 
Dalal, R. S. (2005). A meta-analysis of the relationship between organizational citizenship behavior and counterproductive work behavior. Journal of Applied Psychology, 90(6), 1241-1255.

Dóci, E., \& Bal, P. M. (2018). Ideology in work and organizational psychology: the responsibility of the researcher. European Journal of Work and Organizational Psychology, 27(5), 558-560.

Kozlowski, S. W., Chen, G., \& Salas, E. (2017). One hundred years of the Journal of Applied Psychology: Background, evolution, and scientific trends. Journal of Applied Psychology, 102(3), 237-253.

Lefkowitz, J. (2008). To prosper, organizational psychology should... expand the values of organizational psychology to match the quality of its ethics. Journal of Organizational Behavior, 29(4), 439-453.

Melé, D. (2012). The firm as a "community of persons": A pillar of humanistic business ethos. Journal of Business Ethics, 106(1), 89-101.

Stiglitz, J. E. (2012). The price of inequality: How today's divided society endangers our future. WW Norton \& Company.

Van De Voorde, K., Paauwe, J., \& Van Veldhoven, M. (2012). Employee well-being and the HRM-organizational performance relationship: a review of quantitative studies. International Journal of Management Reviews, 14(4), 391-407.

Žižek, S. (1989). The sublime object of ideology. Verso.

Žižek, S. (2014). Trouble in Paradise: From the End of History to the End of Capitalism. London: Melville house. 